\title{
Treatment of advanced hepatocellular carcinoma with very low levels of amplitude-modulated electromagnetic fields
}

\author{
FP Costa*,', AC de Oliveira', R Meirelles', MCC Machado', T Zanesco', R Surjan', MC Chammas², \\ M de Souza Rocha ${ }^{2}$, D Morgan ${ }^{3}$, A Cantor ${ }^{4}$, J Zimmerman ${ }^{5}$, I Brezovich ${ }^{6}$, N Kuster ${ }^{7}$, A Barbault ${ }^{8}$ \\ and B Pasche ${ }^{*, 5}$
}

'Department of Transplantation and Liver Surgery, Hospital das Clínicas da Faculdade de Medicina, University of São Paulo, Av. Dr. Enéas de Carvalho Aguiar, 255, São Paulo 05403-000, Brazil; ²Department of Radiology, Hospital das Clínicas, University of São Paulo, São Paulo 05403-000, Brazil; ${ }^{3}$ Department of Radiology, University of Alabama at Birmingham and UAB Comprehensive Cancer Center, Birmingham, AL 35294, USA; ${ }^{4}$ Biostatistics and Bioinformatics Shared Facility, University of Alabama at Birmingham and UAB Comprehensive Cancer Center, Birmingham, AL 35294, USA; ${ }^{5}$ Division of Hematology/Oncology, Department of Medicine, University of Alabama at Birmingham and UAB Comprehensive Cancer Center, I 802 6th Ave South, NP 2566, Birmingham, AL 35294-3300, USA; 'Department of Radiation Oncology, The University of Alabama at Birmingham and UAB Comprehensive Cancer Center, Birmingham, AL 35294, USA; ${ }^{7}$ IT'IS Foundation, Swiss Federal Institute of Technology, Zurich, Switzerland; ${ }^{8}$ Rue de Verdun 20, Colmar 68000, France

BACKGROUND: Therapeutic options for patients with advanced hepatocellular carcinoma (HCC) are limited. There is emerging evidence that the growth of cancer cells may be altered by very low levels of electromagnetic fields modulated at specific frequencies. METHODS: A single-group, open-label, phase I/II study was performed to assess the safety and effectiveness of the intrabuccal administration of very low levels of electromagnetic fields amplitude modulated at HCC-specific frequencies in $4 \mathrm{I}$ patients with advanced HCC and limited therapeutic options. Three-daily 60-min outpatient treatments were administered until disease progression or death. Imaging studies were performed every 8 weeks. The primary efficacy end point was progression-free survival $\geqslant 6$ months. Secondary efficacy end points were progression-free survival and overall survival.

RESULTS: Treatment was well tolerated and there were no NCl grade 2, 3 or 4 toxicities. In all, I 4 patients (34. I\%) had stable disease for more than 6 months. Median progression-free survival was 4.4 months $(95 \% \mathrm{Cl} 2.1-5.3)$ and median overall survival was 6.7 months (95\% Cl 3.0-10.2). There were three partial and one near complete responses.

CONCLUSION: Treatment with intrabuccally administered amplitude-modulated electromagnetic fields is safe, well tolerated, and shows evidence of antitumour effects in patients with advanced HCC.

British Journal of Cancer (201 I) 105, 640-648. doi:I0.1038/bjc.201 I.292 www.bjcancer.com

Published online 9 August 2011

(c) 20II Cancer Research UK

Keywords: hepatocellular carcinoma; phase II study; radiofrequency electromagnetic fields; tumour-specific modulation frequencies; 27. $12 \mathrm{MHz}$

Treatment of inoperable or metastatic solid tumours is a major challenge in oncology, which is limited by the small number of therapeutic agents that are both well tolerated and capable of longterm control of tumour growth. Hepatocellular carcinoma (HCC) is the second most common cause of cancer death in men and the sixth in women worldwide (Jemal et al, 2011). Hepatocellular carcinoma is the most common tumour in certain parts of the world, particularly in East Asia, Africa, and certain countries of South America. This tumour is less frequent in Europe and in the United States, but has become the fastest rising cancer in the United States (Jemal et al, 2011). In the United States alone, it is estimated that 24120 new cases were diagnosed and there were 17430 deaths from HCC in 2010 (Jemal et al, 2010), a 27\% increase in the number of new cases since 2004 (Jemal et al, 2004). The

*Correspondence: Dr FP Costa; E-mail: fredericoperegocosta@gmail.com or Dr B Pasche; E-mail: Boris.Pasche@ccc.uab.edu

Revised 4 July 201।; accepted 6 July 201 I; published online 9 August 20II prognosis of patients suffering from advanced HCC is poor with an average survival of fewer than 6 months (Kassianides and Kew, 1987; Jemal et al, 2011).

Therapies for HCC are limited. Resections of the primary tumour or liver transplantation are the preferred therapeutic approaches in patients who are surgical candidates (Bruix and Sherman, 2005). Although these interventions result in long-term survival for some patients, only a minority benefit from them because of limitations due to tumour size, patient's overall condition, and presence of hepatic cirrhosis (Cance et al, 2000). Only a small number of randomised trials show a survival benefit in the treatment of HCC. Chemoembolisation has been shown to confer a survival benefit in selected patients with unresectable HCC (Llovet et al, 2002). Data from two phase III randomised placebo-controlled studies demonstrate improved survival in patients with advanced HCC receiving the multikinase inhibitor sorafenib (Llovet et al, 2008b; Cheng et al, 2009). Additional therapies for this disease are sorely needed, especially for the large number of patients with advanced disease who cannot tolerate 
A

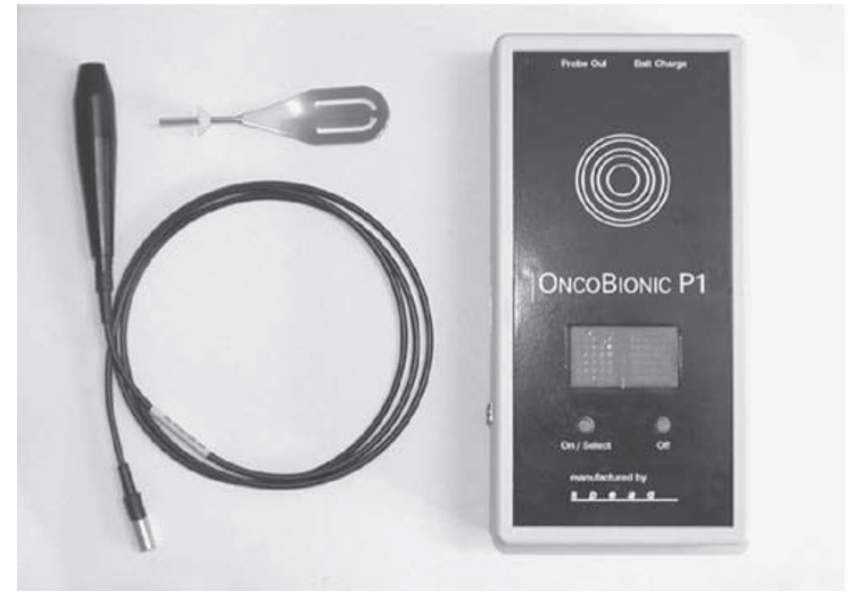

Tumour-specific modulation frequencies range between $100 \mathrm{~Hz}$ and $21 \mathrm{kHz}$

B

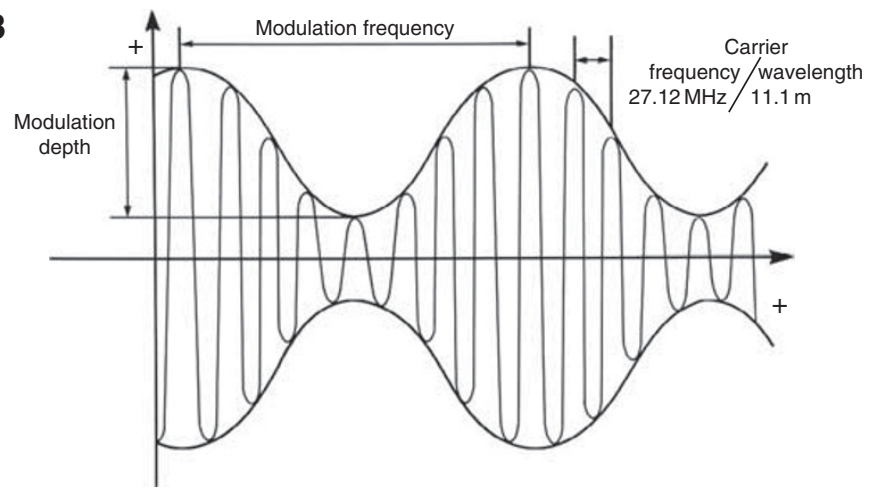

C
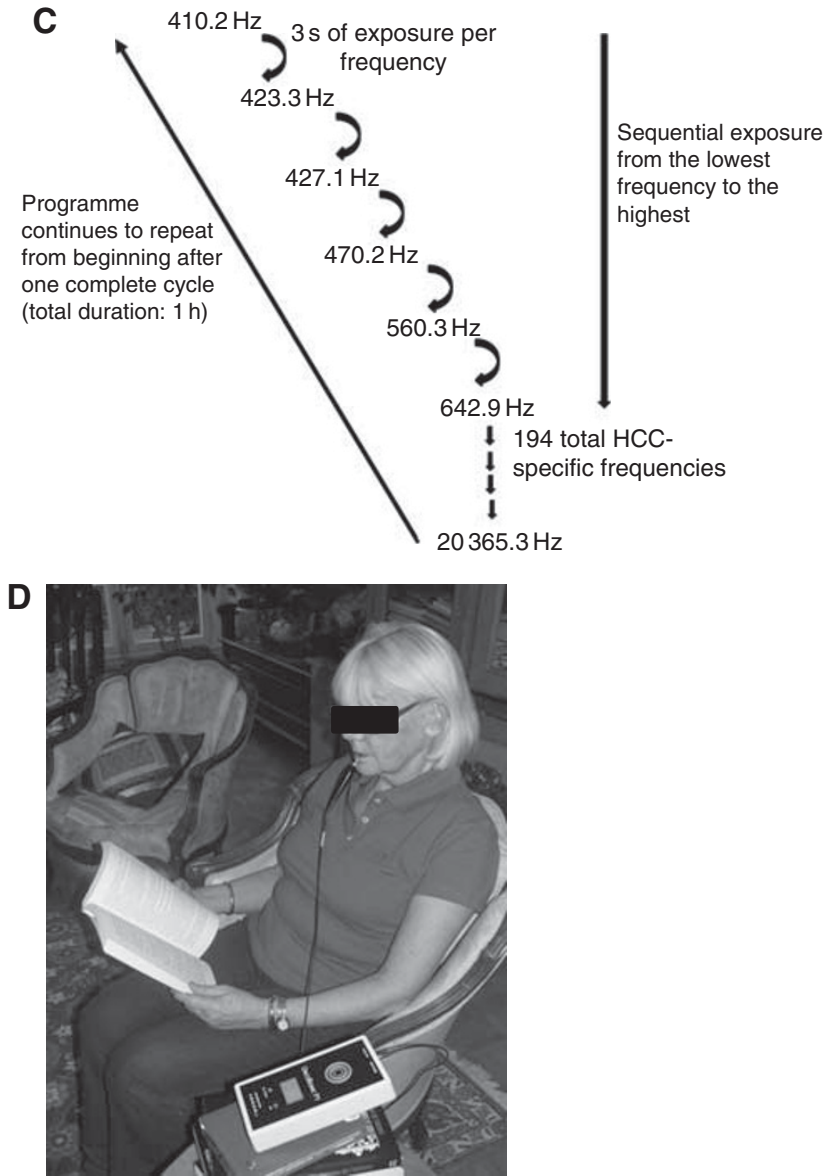

Figure I Delivery of HCC-specific modulation frequencies. (A) The generator of AM EMFs is a battery-driven RF EMF generator connected to a spoonshaped mouthpiece. (B) Schematic description of AM EMFs. The carrier frequency $(27.12 \mathrm{MHz}$ ) is sinusoidally modulated at specific frequencies. (C) Patient receiving treatment with RF AM EMF. (D) HCC treatment programme consisting of sequential emission of 194 modulation frequencies for 60 min.

chemotherapy or intrahepatic interventions because of impaired liver function (Thomas and Zhu, 2005).

The intrabuccal administration of low and safe levels of electromagnetic fields, which are amplitude-modulated at disease-specific frequencies (RF AM EMF) (Figure 1), was originally developed for the treatment of insomnia (Pasche et al, 1990). The highest levels of EMFs encountered during treatment are found at the interface between the tongue and the mouth probe and are compliant with international safety limits (ICNIRP, 1998; Pasche and Barbault, 2003). Tumour-specific modulation frequencies have been identified for several common forms of cancer and one report suggests that this novel therapeutic approach is well tolerated and may be effective in patients with a diagnosis of cancer (Barbault et al, 2009). However, the safety and potential efficacy of this treatment approach in the treatment of advanced HCC are unknown. We designed this single-group, open-label, phase I/II study to assess the feasibility of this treatment in patients with advanced HCC and limited therapeutic options.

\section{PATIENTS AND METHODS}

\section{Patients}

The study was aimed at offering treatment to patients with ChildPugh A or B advanced HCC and limited therapeutic options. Patients were classified as having advanced disease if they were not eligible for surgical resection or had disease progression after surgical or locoregional therapies or had disease progression after chemotherapy or sorafenib therapy. Patients with measurable, inoperable HCC were eligible for enrolment. Previous local or systemic treatments were allowed as long as they were discontinued at least 4 weeks before enrolment. Inclusion criteria included Eastern Cooperative Oncology Group performance status of 0,1 , or 2 and biopsy-confirmed HCC. Also allowed were patients with no pathological confirmation of HCC with a level of $\alpha$-fetoprotein higher than $400 \mathrm{ng} \mathrm{ml}^{-1}$ and characteristic imaging findings as assessed by multislice computer tomography (CT) scan or intravenous contrast ultrasound (US). As per the University of São Paulo Department of Transplantation and Liver Surgery guidelines, liver biopsies are avoided in patients eligible for transplant or with severely impaired liver function. Exclusion criteria included confirmed or suspected brain metastasis, Child-Pugh C, previous liver transplant, and pregnancy.

\section{Study design}

This was an investigator-initiated, single centre, uncontrolled phase I/II trial in patients with advanced HCC. The trial was approved by the local human investigation committee and conducted in accordance with the Declaration of Helsinki. Written informed consent was obtained from each patient. The protocol was registered: clinicaltrial.gov identifier no. NCT00534664. 
Consort diagram

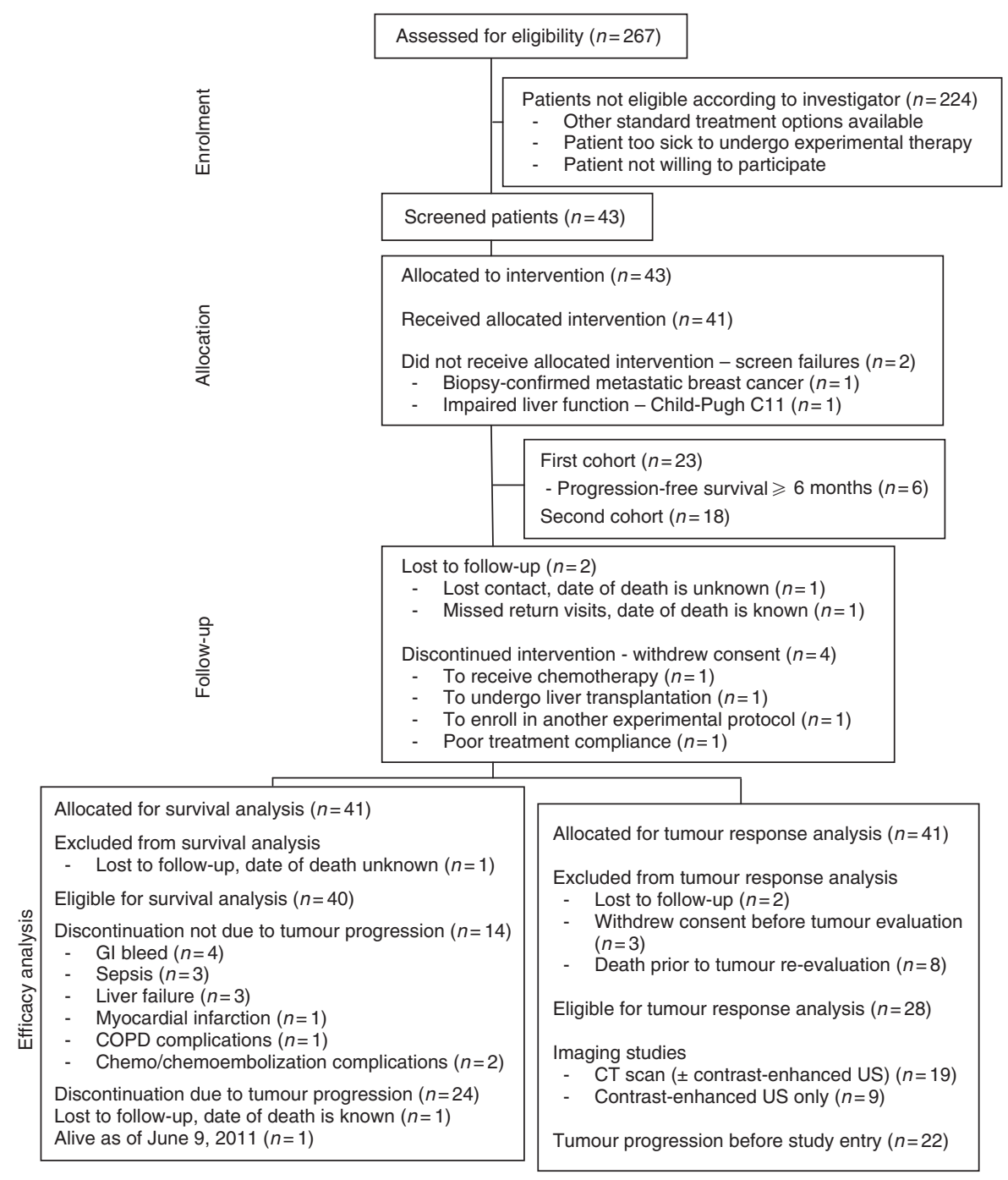

Figure 2 CONSORT diagram.

\section{Administration of AM EMFs}

The generator of AM EMFs consists of a battery-driven radiofrequency (RF) EMF generator connected to a $1.5 \mathrm{~m}$ long $50 \Omega$ coaxial cable, to the other end of which a stainless-steel spoonshaped mouthpiece is connected via an impedance transformer (Figure 1A). The RF source of the device corresponds to a class $\mathrm{C}$ amplifier operating at $27.12 \mathrm{MHz}$. The carrier frequency is AM (Figure 1B) with a modulation depth of $85 \pm 5 \%$, whereas the modulation frequency is generated by a digital direct synthesiser with a resolution of $10^{-7}$. The treatment sequence is controlled by a microcontroller (Atmel AT89S8252, Fribourg, Switzerland), that is, duration of session, sequence of modulation frequencies and duration of each sequence can be programmed via PC over a RS232 interface. The RF output is adjusted to $100 \mathrm{~mW}$ into a $50 \Omega$ load, which results in an emitting power identical to that of the device used for the treatment of insomnia (Pasche et al, 1990; Reite et al, 1994; Pasche et al, 1996). The United States Food and Drug Administration has determined that such a device is not a significant risk device and it has been used in several studies conducted in the United States (Reite et al, 1994; Pasche et al, 1996; Kelly et al, 1997). A long-term follow-up survey of 807 patients who have received this therapy in the United States, Europe and
Asia showed that the rate of adverse reactions was low and was not associated with increases in the incidence of malignancy or coronary heart disease (Amato and Pasche, 1993). The maximum specific absorption rate (SAR) of the applied RF averaged over any $10 \mathrm{~g}$ of tissue has been estimated to be less than $2 \mathrm{~W} \mathrm{~kg}^{-1}$, and the maximum temperature increase is significantly lower than $1^{\circ} \mathrm{C}$ anywhere in the body owing to RF absorption. The induced RF field values within the primary and metastatic tumours are significantly lower. In contrast, the RF fields induced during RF ablation of tumours cause hyperthermia and result in SAR in the range of $2.4 \times 10^{5} \mathrm{~W} \mathrm{~kg}^{-1}$ (Chang, 2003), that is, more than 100000 times higher than those delivered by the device used in this study.

We have previously reported the discovery of HCC-specific modulation frequencies in 46 patients with HCC using a patientbased biofeedback approach and shown the feasibility of using AM EMFs for the treatment of patients with cancer (Barbault et al, 2009). The treatment programme used in this study consisted of three-daily outpatient treatments of $1 \mathrm{~h}$ duration, which contained HCC-specific modulation frequencies ranging between $100 \mathrm{~Hz}$ and $21 \mathrm{kHz}$ administered sequentially, each for $3 \mathrm{~s}$ (Figure $1 \mathrm{C}$ and Supplementary Table S1).

The treatment method consists of the administration of AM EMFs by means of an electrically conducting mouthpiece, which is 
in direct contact with the oral mucosa (Figure 1D). The patients were instructed on the use of the device and received the first treatment at the medical centre's outpatient clinic. A device was provided to each patient for the duration of the study. The patients were advised to self-administer treatment three times a day. Treatment was administered until tumour progression was objectively documented. At that time, treatment was discontinued. Treatment compliance was assessed at every return visit by recording the number of treatments delivered in the preceding 2 months.

\section{Efficacy end points and disease assessment}

The primary end point of this trial was the proportion of patients progression-free at 6 months. Secondary end points were progression-free survival (PFS) (first day of treatment until progression of disease or death) and overall survival (OS) (first day of receiving treatment to death). Objective response was assessed using the Response Evaluation Criteria in Solid Tumours group classification for patients with disease assessed by either helical multiphasic CT (Therasse et al, 2000). Whenever contrastenhanced US radiological assessment was used, it was performed and reviewed by the same radiologist specialised in HCC (MCC) as this imaging modality is investigator dependent. Tumour measurements were performed at baseline and every 8 weeks. Only patients with at least one repeat tumour measurement during therapy were considered for response analysis. Throughout the study, lesions measured at baseline were evaluated using the same technique (CT or contrast-enhanced US). Overall tumour response was scored as a complete response (CR), partial response (PR), or stable disease (SD) if the response was confirmed at least 4 weeks later. Alpha-fetoprotein (AFP) levels were measured every 8 weeks in all patients throughout the study, but changes in AFP were not an end point for assessment of response. Pain was assessed according to the NCI-CTCAE v.3.0 (http://ctep.cancer.gov/protocolDevelopment/electronic_applications/docs/ctcaev3.pdf).

\section{Statistical analyses and efficacy assessment}

All eligible patients who began treatment were considered assessable for the primary and secondary end points. A Simon two-stage phase II minimax design was used (Simon, 1989) to evaluate the rate of progression-free survival at 6 months. The interim analysis was performed once enrolment into the first stage was completed. In the first stage, 23 patients were observed. If two or fewer patients had progression-free survival $\geqslant 6$ months, the trial would be terminated early for lack of efficacy. If the progression-free survival of 3 or more of the first 23 patients was equal or greater than 6 months, then an additional 18 patients would be enrolled to a maximum of 41 patients. If eight or more of the 41 had PFS of at least 6 months, we would conclude that the treatment was efficacious. This design had a Type I error rate of $5 \%$ and a Type II error rate of $10 \%$ for the null hypothesis of a 6 -month PFS rate of $10 \%$ vs the alternative of $27.5 \%$. KaplanMeier estimates of survival, PFS, and duration of response were calculated with standard errors based on Greenwood's formula. These calculations were performed using the Proc Lifetest in SAS 9.2 (SAS Institute Inc., Cary, NC, USA).

\section{RESULTS}

\section{Patient recruitment and follow-up}

From October 2005 to July 2007, 267 patients were assessed for eligibility (Figure 2). In all, 43 patients with advanced HCC and Child-Pugh A or B were enrolled in this study. The date of last patient follow-up is 9 June 2011 . Of these, 20 patients $(46.5 \%)$ had histological confirmation of HCC; 23 patients $(53.5 \%)$ were
Table I Treatments received by patients with advanced HCC before enrolment $(n=4 I)$

No previous treatment

Chemoembolisation

131-Lipiodol

Octreotide

Percutaneous alcohol injection therapy

Surgery

Systemic chemotherapy or sorafenib

Abbreviation: HCC = hepatocellular carcinoma. Two patients had surgery and chemoembolisation, two patients had surgery and systemic chemotherapy, one patient had surgery and chemoembolisation and systemic chemotherapy, one patient had surgery and percutaneous alcohol injection, one patient had surgery and sorafenib, one patient had chemoembolisation and systemic chemotherapy and one patient had surgery and octreotide.

Table 2 Patients' baseline characteristics

\begin{tabular}{|c|c|c|}
\hline & No. & $\%$ \\
\hline \multicolumn{3}{|l|}{ Age (years) } \\
\hline Median age & 64 & \\
\hline Range & $18-85$ & \\
\hline$\geqslant 65$ & 19 & 46.3 \\
\hline$<65$ & 22 & 53.6 \\
\hline \multicolumn{3}{|l|}{ Sex } \\
\hline Female & 6 & 14.6 \\
\hline Male & 35 & 85.4 \\
\hline \multicolumn{3}{|l|}{ ECOG performance status } \\
\hline 0 & 5 & 12.2 \\
\hline । & 28 & 68.3 \\
\hline 2 & 8 & 19.5 \\
\hline \multicolumn{3}{|l|}{ Child-Pugh status } \\
\hline A5 & 15 & 36.6 \\
\hline A6 & 2 & 4.9 \\
\hline B7 & 6 & 14.6 \\
\hline B8 & 5 & 12.2 \\
\hline B9 & | | & 26.8 \\
\hline No cirrhosis & 2 & 4.9 \\
\hline \multicolumn{3}{|l|}{ BCLC status } \\
\hline$B$ & 6 & 14.6 \\
\hline C & 35 & 85.4 \\
\hline \multicolumn{3}{|l|}{$A F P>U L N$} \\
\hline Yes & 28 & 68.3 \\
\hline No & 13 & 16.7 \\
\hline \multicolumn{3}{|l|}{ Aetiology } \\
\hline ETOH & 2 & 4.9 \\
\hline Hepatitis B & 6 & 14.6 \\
\hline Hepatitis B+C & 1 & 2.4 \\
\hline Hepatitis C & 22 & 53.7 \\
\hline ETOH+hepatitis C & । & 2.4 \\
\hline NOS & 9 & 22.0 \\
\hline Portal thrombosis & 10 & 24.3 \\
\hline \multicolumn{3}{|l|}{ Extrahepatic disease } \\
\hline Yes & 16 & 39.0 \\
\hline \multicolumn{3}{|l|}{ Location } \\
\hline Lung & 6 & 14.6 \\
\hline Bone & 3 & 7.3 \\
\hline Lymph nodes & 4 & 9.8 \\
\hline Peritoneal carcinomatosis & I & 2.4 \\
\hline Adrenal gland & I & 2.4 \\
\hline
\end{tabular}

Abbreviations: $\quad \mathrm{AFP}=\alpha$-fetoprotein; $\quad \mathrm{BCLC}=$ Barcelona Clinic Liver Cancer; $\mathrm{ECOG}=$ Eastern Cooperative Oncology Group; ETOH, ethyl alcohol; ULN, upper limit of normal. 

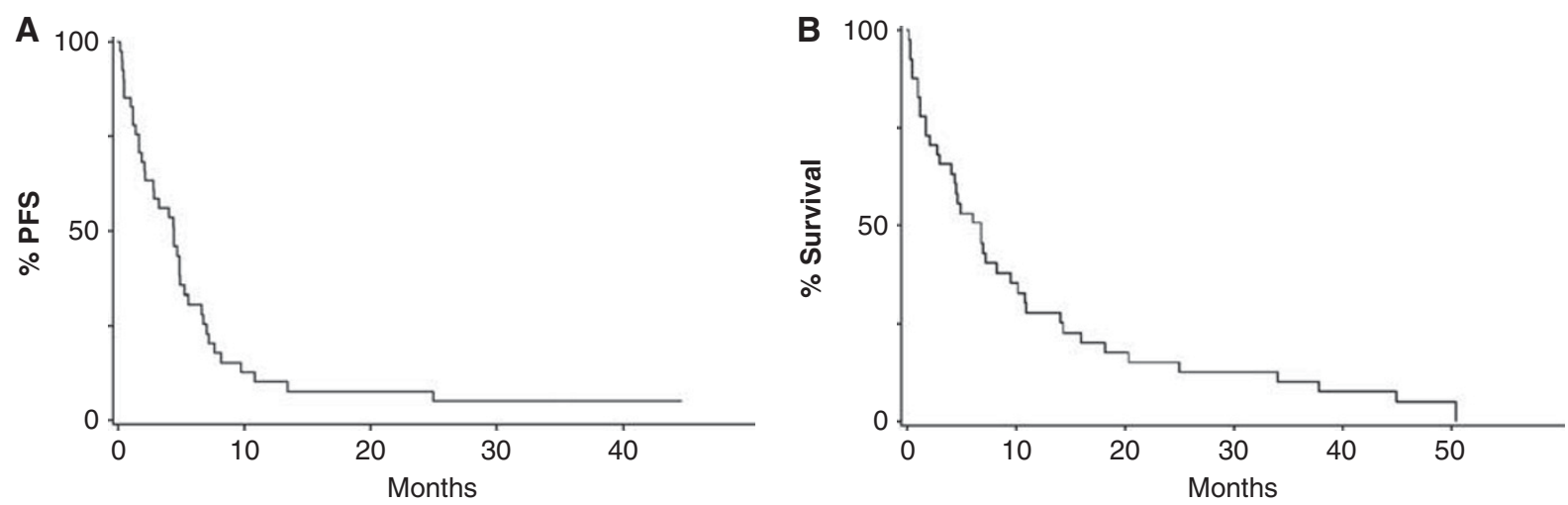

C

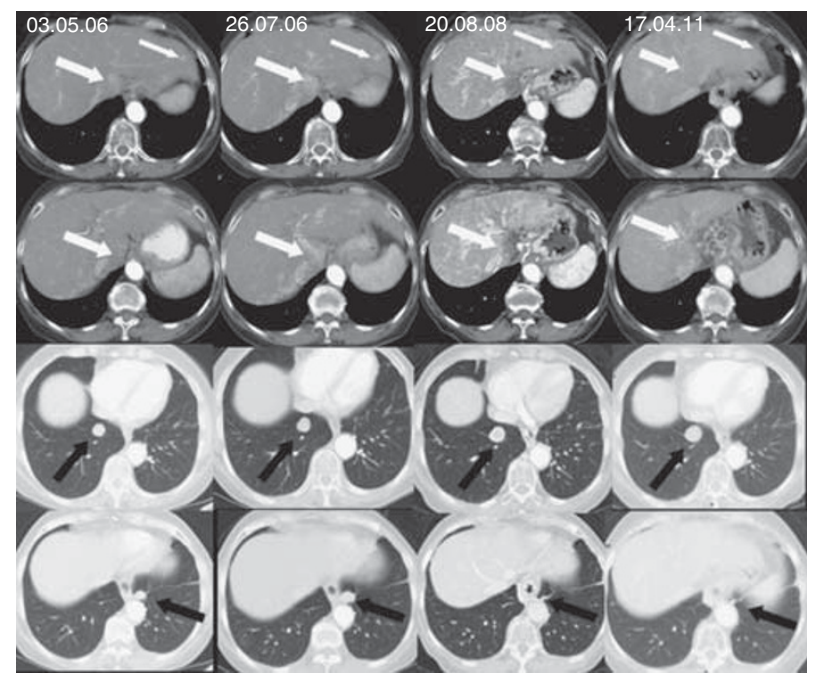

d

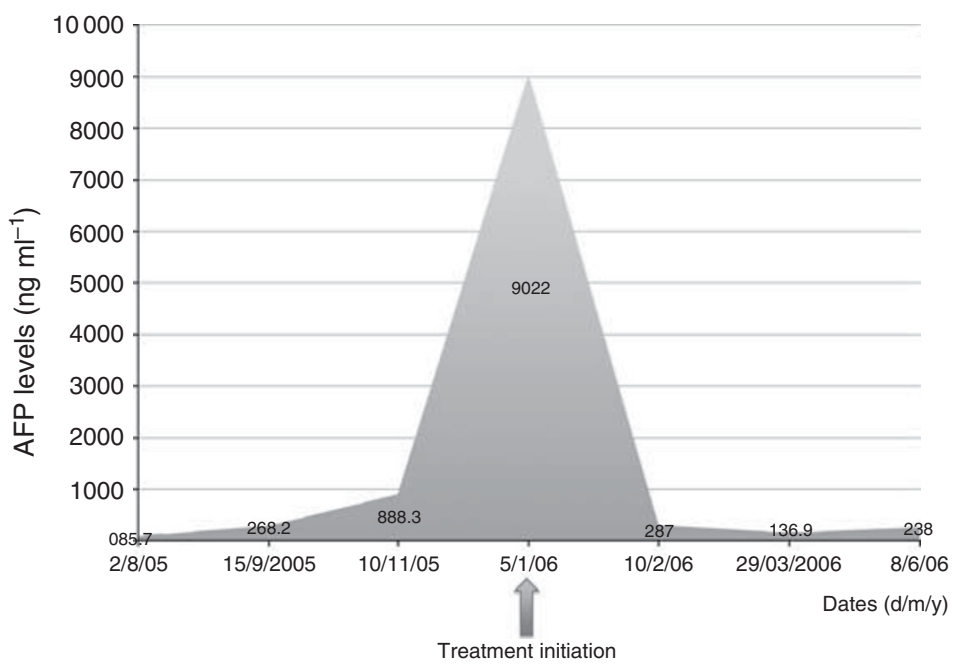

Figure 3 Progression-free and overall survival. (A) Median progression-free survival was 4.4 months $(95 \% \mathrm{Cl} 2.1-5.3)$. (B) Median overall survival was 6.7 months (95\% Cl 3.0-10.2). (C) Long-term partial response in a patient with biopsy-proven hepatocellular carcinoma. A 76-year-old woman with hepatitis $C$ and Child-Pugh A5, BCLC C, biopsy-proven hepatocellular carcinoma with bilateral pulmonary metastases, who had evidence of disease progression ( $+36 \%$ by Response Evaluation Criteria in Solid Tumours (RECIST) criteria) between 3 May 2006 (first column) and 26 July 2006 (second column) while enrolled in the SHARP study (Llovet et al, 2008b). Treatment with AM EMFs was initiated on 9 August 2006. Subsequent restaging multiphasic contrastenhanced computed tomographies (CTs) with images from corresponding levels (across rows) are demonstrated in the third and fourth columns over the course of 57 months. Note that the hypervascularity of the focal hepatic lesions (arrows in first two rows) became relatively hypoenhancing on arterial phase (20 August 2008). The patient developed main portal vein thrombosis with cavernous transformation as a complication of her cirrhosis. However, the intrahepatic lesion size is stable regardless of enhancement pattern. Note also that the left lung base lesion resolved (4th row), and the right lung base lesion remained stable (3rd row) over the duration of treatment. (D) Alpha-fetoprotein response in a 67-year-old patient with Child-Pugh A5, BCLC C HCC and hepatitis C (hepatitis B negative).

diagnosed based on elevated levels of $\alpha$-fetoprotein and characteristic imaging findings such as vascular invasion and characteristic differences in tumour blood flow. One patient was excluded because liver biopsy established the diagnosis of metastatic breast cancer. Another patient was excluded because of severely impaired liver function (Child-Pugh C11). These two patients who did not meet the inclusion criteria were registered as screening failures. Hence, a total of 41 patients were eligible to receive experimental therapy (Figure 2).

Two patients were lost to follow-up as they did not come back for their scheduled appointments. Repeated efforts were made to reach the patients and their families. The date of death of only one patient is known, and no information on response to treatment is available for either patient. Four patients withdrew consent while receiving therapy after 8.0, 9.3, 20.3, and 21.0 months, respectively (Figure 2). One patient elected to receive chemotherapy, one patient had poor treatment compliance as defined by administration of less than $50 \%$ of planned treatments at two consecutive return visits, one patient elected to enrol in another experimental protocol, and one patient requested to be considered for liver transplantation as part of an extended indication, which does not fulfil the Milan criteria (Mazzaferro et al, 1996). This latter patient experienced disease progression and was ultimately not eligible for liver transplantation. Of the 35 patients who discontinued experimental therapy, four died of gastrointestinal bleeding, three of sepsis, three of hepatic failure, one of chronic obstructive pulmonary disease, two of chemotherapyand chemoembolisation-related complications, and one of myocardial infarction (Figure 2). The remaining 24 patients discontinued because of disease progression assessed by imaging or significant clinical deterioration as assessed by the investigator (Figure 2). Estimated 60 -day mortality was $27.8 \%$; seven of 10 deaths were directly related to progression of disease. They were caused by liver failure in association with significant hepatic tumour involvement, without other cause of death, other than tumour involvement. Two deaths were secondary to gastrointestinal bleeding. One death was due to liver failure. 
A total of 31 patients $(75.6 \%)$ had radiological evidence of disease progression at the time of enrolment as defined by comparison of baseline imaging studies, with imaging studies obtained within the previous 6 months; $34(82.9 \%)$ patients had received therapy before enrolment, five $(14.6 \%)$ of them systemic chemotherapy or sorafenib (Table 1$)$. Seven $(17.1 \%)$ patients had not received therapy before enrolment for the following reasons: (1) severely impaired liver function in five cases; and (2) two patients refused to receive chemotherapy for metastatic disease. As shown in Table 2, the majority of patients had severely impaired liver function as demonstrated by the fact that $22(53.7 \%)$ patients had Child-Pugh B disease and 35 (85.4\%) BLCL stage C disease.

Table 3 Independently reviewed best response $(N=4 I)$

\begin{tabular}{lrr}
\hline Best response & No. & $\%$ \\
\hline Partial response $^{\text {a }}$ & 4 & 9.8 \\
Stable disease $^{b}$ & 16 & 39.0 \\
Progressive disease $_{\text {Not available for response assessment }}$ & 8 & 19.5 \\
\hline
\end{tabular}

a Duration of the partial responses were $+58.0,46.9,14.5$ and 5.3 months (patient withdrew consent to undergo liver transplant). ${ }^{\mathrm{b}}$ To be classified as a stable disease, patients needed to have stable disease for $\geqslant 12$ weeks.

\section{Treatment efficacy}

Six of the first 23 patients $(26.1 \%)$ had progression-free survival $\geqslant 6$ months, which led us to continue enrolling patients up to the preplanned total of 41 patients (Figure 2). In total, 14 patients (34.1\%) had SD for more than 6 months, which met our preplanned primary efficacy end point. Median progression-free survival was 4.4 months (95\% CI 2.1-5.3) and median OS was 6.7 months (95\% CI 3.0-10.2) (Figure 3A and B). One patient, previously enrolled in the SHARP study (Llovet et al, 2008b) and with evidence of disease progression at the time of enrolment, remains on therapy with a near complete response for 58 months (Figure 3C). Estimated survival at 12,24 and 36 months is $27.9 \%$ (s.e. $=7.1 \%$ ), $15.2 \%$ (s.e. $=5.7 \%$ ), and $10.1 \%($ s.e. $=4.8 \%$ ), respectively. Subset analyses by Child-Pugh stage and accompanying figures are reported in Supplementary Information.

A total of 28 patients were evaluable for tumour response (Figure 2). Four (9.8\%) patients had a partial response assessed with CT with or without contrast-enhanced ultrasound (Table 3). All partial responses were independently reviewed by two authors (MSR and DM). Three patients had biopsy-confirmed HCC and three had radiological evidence of disease progression at the time of enrolment (Table 4). Two patients had Child-Pugh A, one Child-Pugh B disease, and one had no cirrhosis. One of these

Table 4 Characteristics of patients with either PR and/or long-term survival in excess of 24 months

\begin{tabular}{|c|c|c|c|c|c|c|c|c|c|c|c|c|c|}
\hline $\begin{array}{l}\text { Age at } \\
\text { enrolment } \\
\text { and sex }\end{array}$ & Race & $\begin{array}{l}\text { Causel } \\
\text { cirrhosis } \\
\text { (Child- } \\
\text { Pugh) }\end{array}$ & $\begin{array}{l}\text { Previous } \\
\text { treatment/ } \\
\text { resection }\end{array}$ & $\begin{array}{c}\text { AFP } \uparrow I \\
\text { pathology } \\
\text { confirmation }\end{array}$ & $\begin{array}{c}\text { Extra hepatic } \\
\text { metastasis/ } \\
\text { portal } \\
\text { thrombosis }\end{array}$ & BCLC & Okuda & CLIP & MELD & $\begin{array}{l}\text { Progression } \\
\text { before study } \\
\text { entryl } \\
\text { response }\end{array}$ & $\begin{array}{l}\text { Treatment } \\
\text { duration/ } \\
\text { overall } \\
\text { survival } \\
\text { (months) }\end{array}$ & $\begin{array}{l}\text { Cause } \\
\text { of } \\
\text { death }\end{array}$ & $\begin{array}{l}\text { Treatment } \\
\text { received after } \\
\text { completion of } \\
\text { experimental } \\
\text { therapy }\end{array}$ \\
\hline $62 M$ & Caucasian & $\begin{array}{l}\text { Hep } \\
\text { Clyes } \\
\text { (A5) }\end{array}$ & Yes/no & Yes/yes & No/no & B & I & 0 & 6 & Yes/N/A & $2.0 / 32.0$ & $\begin{array}{l}\text { Tumour } \\
\text { progressed }\end{array}$ & $\begin{array}{l}\text { Systemic } \\
\text { chemotherapy }\end{array}$ \\
\hline $67 \mathrm{~F}$ & Caucasian & $\begin{array}{l}\text { Hep } \\
\text { Clyes } \\
\text { (B9) }\end{array}$ & Yes/no & Yes/yes & No/no & C & 2 & 2 & 11 & Yes/PR & $11.7 / 1 \mid .7$ & Gl bleed & None \\
\hline $30 M$ & Black & NOS/no & Yes/es & No/yes & No/no & B & $N / A$ & N/A & N/A & No/PR & 13.5/37.6 & $\begin{array}{l}\text { Tumour } \\
\text { progressed }\end{array}$ & $\begin{array}{l}\text { Chemoembolisation } \\
\text { and systemic } \\
\text { chemotherapy }\end{array}$ \\
\hline $61 \mathrm{M}$ & Caucasian & $\begin{array}{l}\text { Hep } \\
\text { Clyes } \\
\text { (A5) }\end{array}$ & Yes/no & $\mathrm{No} / \mathrm{no}$ & No/no & C & I & । & 6 & Yes/SD & $26.8 / 26.8$ & COPD & None \\
\hline $56 M$ & Caucasian & $\begin{array}{l}\text { Hep } \\
\text { B/C/yes } \\
\text { (A5) }\end{array}$ & $\mathrm{No} / \mathrm{no}$ & Yes/no & No/no & B & I & 0 & 10 & Yes/SD & $4.9 / 50.3$ & $\begin{array}{l}\text { Tumour } \\
\text { progressed }\end{array}$ & Chemoembolisation \\
\hline $63 M$ & Caucasian & $\begin{array}{l}\text { Hep } \\
\text { Clyes } \\
\text { (A5) }\end{array}$ & Yes/no & Yes/no & No/no & C & I & । & 4 & Yes/PR & $4.9 / / 4.3$ & $\begin{array}{l}\text { Tumour } \\
\text { progressed }\end{array}$ & None \\
\hline $76 \mathrm{~F}$ & Caucasian & $\begin{array}{l}\text { Hep } \\
\text { Clyes } \\
\text { (A5) }\end{array}$ & $\mathrm{No} / \mathrm{no}$ & $\mathrm{No} /$ no & Nolyes & C & 1 & । & 6 & Yes/SD & $44.6 / 44.6$ & $\begin{array}{l}\text { Tumour } \\
\text { progressed }\end{array}$ & None \\
\hline $76 \mathrm{~F}$ & Caucasian & $\begin{array}{l}\text { Hep } \\
\text { Clyes } \\
\text { (A5) }\end{array}$ & No/yes & No/yes & Yes/yes & C & I & । & 6 & Yes/PR & $+58.0 /+58.0$ & On therapy & $\begin{array}{l}\text { Still receiving } \\
\text { experimental } \\
\text { treatment }\end{array}$ \\
\hline
\end{tabular}

Abbreviations: $\mathrm{AFP}=\alpha$-fetoprotein; $\mathrm{BCLC}=$ Barcelona Clinic Liver Cancer, CLIP = Cancer Liver Italian Programme; $\mathrm{Gl}=$ gastrointestinal; MELD = Model for end-stage liver disease; $N / A=$ not applicable; $P R=$ partial response; $S D=$ stable disease.

Table 5 Changes in AFP levels

\begin{tabular}{|c|c|c|c|c|c|c|c|}
\hline $\begin{array}{l}\text { Patient age } \\
\text { and gender }\end{array}$ & $\begin{array}{l}\text { AFP } 6 \text { months } \\
\left(\mathrm{ng} \mathrm{ml}^{-1}\right)\end{array}$ & 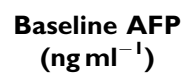 & $\begin{array}{l}\text { 8-week AFP } \\
\left(\mathrm{ng} \mathrm{ml}^{-1}\right)\end{array}$ & $\begin{array}{l}\text { AFP variation } \\
\text { (\%) }\end{array}$ & $\begin{array}{c}\text { Treatment duration } \\
\text { (months) }\end{array}$ & $\begin{array}{l}\text { End treatment } \\
\text { status }\end{array}$ & $\begin{array}{l}\text { Virus } \\
\text { status }\end{array}$ \\
\hline $65 M$ & 4.31 & 9.76 & 5.95 & -39.0 & 3.0 & Progression-death & HepC \\
\hline $64 M$ & 4.7 & 4.5 & 2.6 & -42.2 & 8.8 & AMI-death & НерВ \\
\hline $18 M$ & 6.7 & 35.7 & 16.4 & -55.7 & 7.8 & Revoked consent-death & NOS \\
\hline
\end{tabular}

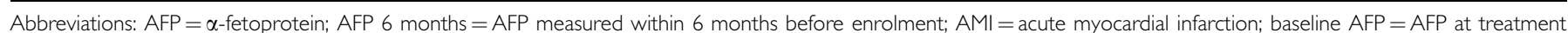
initiation; $\mathrm{Gl}=$ gastrointestinal; $\mathrm{HepB}=$ hepatitis $\mathrm{B}$ virus; HepC = hepatitis $\mathrm{C}$ virus; $\mathrm{NOS}=$ not otherwise specified; 8 -week AFP $=$ AFP at 8 weeks during treatment. 
patients without biopsy-proven disease subsequently withdrew consent after 4.9 months to undergo liver transplantation. The patient died of progression of disease 9.4 months later before undergoing liver transplantation. One patient with Child-Pugh B disease had a partial response lasting 11.7 months and died of gastrointestinal bleeding. One patient died of disease progression at 44.6 months. Overall, there were six long-term survivors with an OS greater than 24 months and four long-term survivors with an OS greater than 3 years. Importantly, five of the six (83\%) long-term survivors had radiological evidence of disease progression at the time of study enrolment (Table 4). Two of three patients with the longest survival (44.6 and +58 months) had radiological evidence of disease progression at the time of enrolment, BLCL stage C disease, as well as portal vein thrombosis, three predictors of short survival (Llovet et al, 2003). Serial AFP measurements, which predict radiological response and survival in patients with HCC (Chan et al, 2009; Riaz et al, 2009), were available for 23 patients. AFP decreased by $20 \%$ or more in four $(9.8 \%)$ patients following initiation of therapy (Table 5). Figure 3D shows the time course of a 37-fold decrease in AFP in a patient who had a long-lasting (11.7 months) partial response as assessed by CT.

In all, 11 patients reported pain before treatment initiation, 3 patients reported grade 3,5 patients reported grade 2, and 3 patients grade 1 . Five patients reported complete disappearance of pain and two patients reported decreased pain shortly after treatment initiation. Two patients reported no changes and two patients reported increased pain. There were no treatment-related grade 2,3 , or 4 toxicities. The only treatment-related adverse events were grade 1 mucositis (one patient) and grade 1 somnolence (one patient) over a total of 266.8 treatment months.

\section{DISCUSSION}

Treatment with AM EMFs did not show any significant toxicity despite long-term treatment. The lack of toxicity experienced by the 41 patients presented in this report as well as the 28 patients from our previous report (Barbault et al, 2009) can be readily explained by the very low and safe levels of induced RF EMFs, which are more than 100000 times lower than those delivered during RF ablation procedures (Chang, 2003). Hence, the putative mechanism of action of this novel therapeutic approach does not depend on temperature changes within the tumour.

These data are comparable to recent phase II studies evaluating the effectiveness of standard chemotherapy as well as novel targeted therapies in HCC (Abou-Alfa et al, 2006; Boige et al, 2007; Chuah et al, 2007; Cohn et al, 2008; Dollinger et al, 2008; Siegel et al, 2008). In a large phase II study assessing the effects of sorafenib in patients with HCC and Child-Pugh A and B who had not received previous systemic treatment, Abou-Alfa et al (2006) observed partial responses using the WHO criteria in $2.2 \%$ of patients. Investigator-assessed median time to progression was 4.2 months, and median OS was 9.2 months. Of note, all 137 patients from that study had evidence of disease progression after 14.8 months (Abou-Alfa et al, 2006), whereas, at the same time point, four $(9.8 \%)$ of the patients enrolled in this study did not have evidence of disease progression. These findings suggest that RF AM EMF may increase the time to radiological progression in advanced HCC.

The majority of patients enrolled in this study had either failed standard treatment options or had severely impaired liver function that limited their ability to tolerate any form of systemic or intrahepatic therapy. Indeed, 16 patients (39.0\%) had Child-Pugh B8 or B9 disease. Among these patients, the median progressionfree survival was 4.4 months (95\% CI 1.6-7.6 months), which is identical to that of the entire group. Five of these 16 patients (31.3\%) received therapy for more than 7.5 months, which indicates that this therapy is well tolerated even in patients with severely impaired liver function.

Previous treatment with standard chemotherapy or sorafenib does not seem to impact the effectiveness of AM EMFs in the treatment of HCC. Indeed, three of the four patients who had a

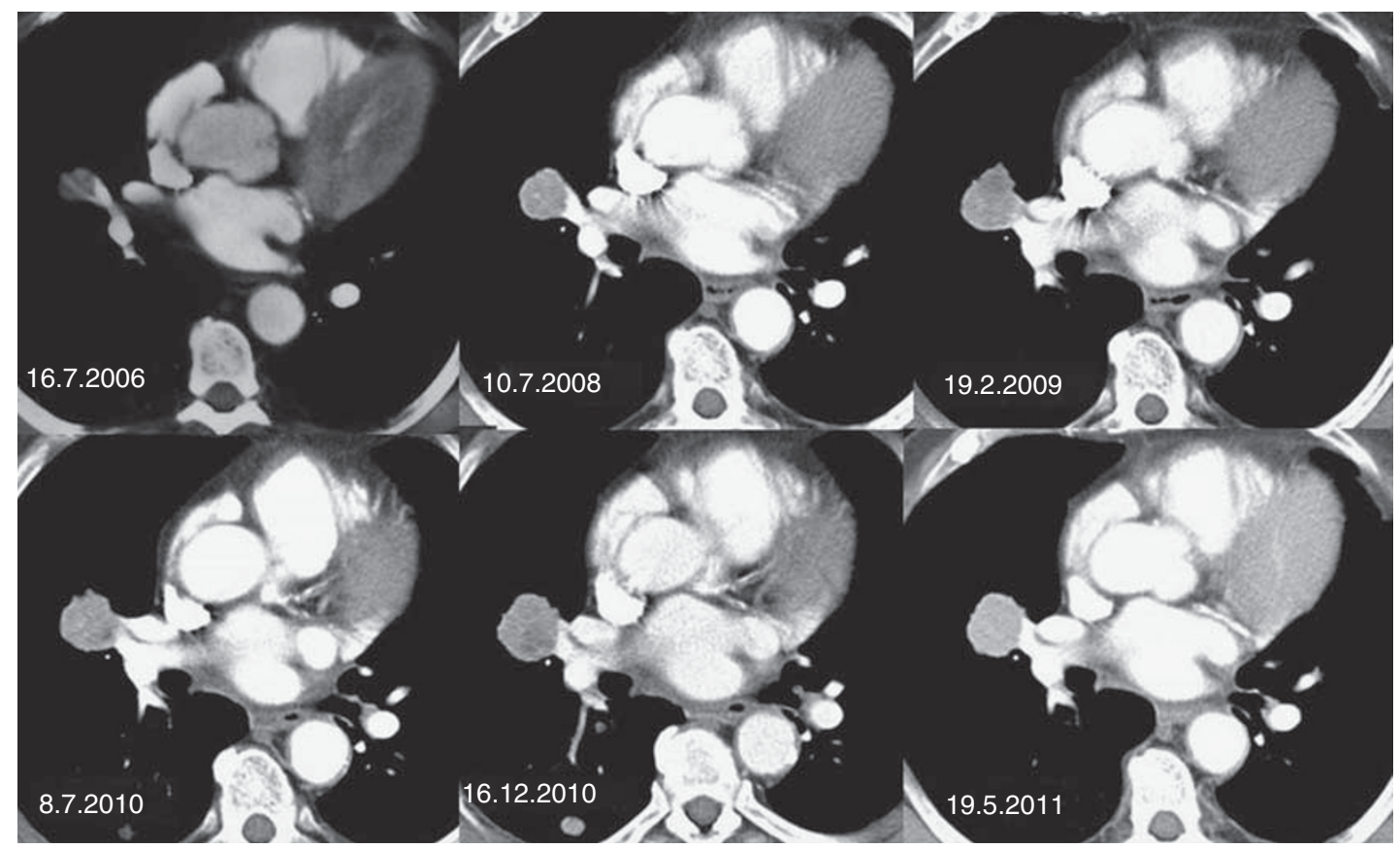

Figure 4 A 70-year-old man with recurrent thyroid cancer metastatic to the lungs: stable disease at 57.5 months. Long-term stable disease in a 70-yearold man with recurrent biopsy-proven thyroid carcinoma metastatic to the lungs enrolled in the previously published feasibility study (Barbault et al, 2009). Treatment with AM EMFs was initiated on 20 August 2006. As of 9 June $201 \mathrm{I}$, the patient is asymptomatic and still receiving treatment with no evidence of disease progression. Images through the target metastatic lesion in the right hilum demonstrate minimal size change over the 4 years, given differences in computed tomography acquisition techniques over that time interval. 
partial response while receiving AM EMFs had received previous systemic therapies (chemotherapy and sorafenib) and one had received intrahepatic therapy with ${ }^{131}$ I-lipiodol.

Tumour shrinkage as assessed by radiological imaging as well as changes in AFP levels were documented in patients with advanced HCC receiving RF EMF modulated at HCC-specific frequencies administered by an intrabuccal probe. Antitumour activity in patients with advanced HCC was exemplified by partial responses observed in four patients (9.8\%) and decreases in AFP levels greater than $20 \%$ in four patients. A total of 18 patients $(43.9 \%)$ either had objective response or SD $\geqslant 6$ months.

Importantly, this therapeutic approach has long-lasting therapeutic effects in several patients with metastatic cancer. Two of these patients, one with recurrent thyroid cancer metastatic to the lungs (Figure 4) enrolled in our feasibility study (Barbault et al, 2009) and the patient shown in Figure 3C, are still receiving treatment without any evidence of disease progression and without side effects almost 5 years after being enrolled in these studies. These findings suggest that, in some patients, this therapeutic approach may achieve permanent control of advanced cancer with virtually no toxicity.

Our phase I/II study has several limitations. First, only 19 of the 41 patients had biopsy-proven HCC, and the others were diagnosed by clinical criteria, an approach similar to that used in a recently reported phase II trial evaluating the clinical and biological effects of bevacizumab in unresectable HCC (Siegel et al, 2008). Importantly, analysis restricted to these 19 patients shows rates of progression-free survival at 6 months, median progression-free survival and OS that are similar to those without biopsyproven HCC (Supplementary Figures 1C and D). Furthermore, three of the four partial responses were observed in patients with biopsy-proven HCC. Hence, these findings strongly suggest that treatment with AM EMFs yields similar results in patients with and without biopsy-confirmed HCC. Another potential limitation of our study consists in the use of contrast-enhanced ultrasound for the monitoring of some patients with HCC. It should be pointed out that recent studies indicate that the use of this imaging technique is comparable to that of CT scan with respect to the measurement of HCC tumours (Choi, 2007; Maruyama et al, 2008).

Antitumour response is considered the primary end point for phase II studies to proceed to further investigations. Studies applying Cox proportional hazards analysis indicate that this end point is consistently associated with survival in trials of locoregional therapies for HCC (Llovet et al, 2002) and a recent consensus article suggests that randomised studies are necessary to capture the true efficacy of novel therapies in HCC (Llovet et al, 2008a). In summary, the encouraging findings from this study warrant a randomised study to determine the impact of AM EMFs on OS and time to symptomatic progression.

\section{ACKNOWLEDGEMENTS}

We thank Drs Al B Benson III, Northwestern University and Leonard B Saltz, Memorial Sloan-Kettering Cancer Center for reviewing the manuscript.

\section{Conflict of interest}

$\mathrm{AB}$ and $\mathrm{BP}$ have filed a patent related to the use of electromagnetic fields for the diagnosis and treatment of cancer. $\mathrm{AB}$ and $\mathrm{BP}$ are founding members of TheraBionic LLC.

Supplementary Information accompanies the paper on British Journal of Cancer website (http://www.nature.com/bjc)

\section{REFERENCES}

Abou-Alfa GK, Schwartz L, Ricci S, Amadori D, Santoro A, Figer A, De GJ, Douillard JY, Lathia C, Schwartz B, Taylor I, Moscovici M, Saltz LB (2006) Phase II study of sorafenib in patients with advanced hepatocellular carcinoma. J Clin Oncol 24(26): 4293-4300

Amato D, Pasche B (1993) An evaluation of the safety of low energy emission therapy (published erratum appears in Compr Ther 1994;20(12):681. Compr Ther 19: $242-247$

Barbault A, Costa F, Bottger B, Munden R, Bomholt F, Kuster N, Pasche B (2009) Amplitude-modulated electromagnetic fields for the treatment of cancer: discovery of tumor-specific frequencies and assessment of a novel therapeutic approach. J Exp Clin Cancer Res 28(1): 51

Boige V, Raoul JL, Pignon JP, Bouche O, Blanc JF, Dahan L, Jouve JL, Dupouy N, Ducreux M (2007) Multicentre phase II trial of capecitabine plus oxaliplatin (XELOX) in patients with advanced hepatocellular carcinoma: FFCD 03-03 trial. Br J Cancer 97(7): 862-867

Bruix J, Sherman M (2005) Management of hepatocellular carcinoma. Hepatology 42(5): 1208-1236

Cance WG, Stewart AK, Menck HR (2000) The National Cancer Data Base Report on treatment patterns for hepatocellular carcinomas: improved survival of surgically resected patients, 1985-1996. Cancer 88(4): $912-920$

Chan SL, Mo FK, Johnson PJ, Hui EP, Ma BB, Ho WM, Lam KC, Chan AT, Mok TS, Yeo W (2009) New utility of an old marker: serial alphafetoprotein measurement in predicting radiologic response and survival of patients with hepatocellular carcinoma undergoing systemic chemotherapy. J Clin Oncol 27(3): 446-452

Chang I (2003) Finite element analysis of hepatic radiofrequency ablation probes using temperature-dependent electrical conductivity. Biomed Eng Online 2: 12

Cheng AL, Kang YK, Chen Z, Tsao CJ, Qin S, Kim JS, Luo R, Feng J, Ye S, Yang TS, Xu J, Sun Y, Liang H, Liu J, Wang J, Tak WY, Pan H, Burock K, Zou J, Voliotis D, Guan Z (2009) Efficacy and safety of sorafenib in patients in the Asia-Pacific region with advanced hepatocellular carcinoma: a phase III randomised, double-blind, placebo-controlled trial. Lancet Oncol 10(1): 25 - 34
Choi BI (2007) Doppler and harmonic ultrasound for hepatocellular carcinoma. Hepatol Res 37(Suppl 2): S172-S177

Chuah B, Lim R, Boyer M, Ong AB, Wong SW, Kong HL, Millward M, Clarke S, Goh BC (2007) Multi-centre phase II trial of Thalidomide in the treatment of unresectable hepatocellular carcinoma. Acta Oncol 46(2): $234-238$

Cohn AL, Myers JW, Mamus S, Deur C, Nicol S, Hood K, Khan MM, Ilegbodu D, Asmar L (2008) A phase II study of pemetrexed in patients with advanced hepatocellular carcinoma. Invest New Drugs 26(4): $381-386$

Dollinger MM, Behrens CM, Lesske J, Behl S, Behrmann C, Fleig WE (2008) Thymostimulin in advanced hepatocellular carcinoma: a phase II trial. BMC Cancer 8: 72

ICNIRP (1998) Guidelines for limiting exposure to time-varying electric, magnetic and electromagnetic fields (up to $300 \mathrm{GHz}$ ). Health Phys 74: $494-522$

Jemal A, Bray F, Center MM, Ferlay J, Ward E, Forman D (2011) Global cancer statistics. Cancer J Clin 61(2): 69-90

Jemal A, Siegel R, Xu J, Ward E (2010) Cancer statistics, 2010. Cancer J Clin 60(5): $277-300$

Jemal A, Tiwari RC, Murray T, Ghafoor A, Samuels A, Ward E, Feuer EJ, Thun MJ (2004) Cancer statistics, 2004. Cancer J Clin 54(1): $8-29$

Kassianides C, Kew MC (1987) The clinical manifestations and natural history of hepatocellular carcinoma. Gastroenterol Clin North Am 16(4): $553-562$

Kelly TL, Kripke DF, Hayduk R, Ryman D, Pasche B, Barbault A (1997) Bright light and LEET effects on circadian rhythms, sleep and cognitive performance. Stress Med 13: $251-258$

Llovet JM, Burroughs A, Bruix J (2003) Hepatocellular carcinoma. Lancet 362(9399): $1907-1917$

Llovet JM, Di Bisceglie AM, Bruix J, Kramer BS, Lencioni R, Zhu AX, Sherman M, Schwartz M, Lotze M, Talwalkar J, Gores GJ, for the Panel of Experts in HCC-Design Clinical Trials (2008a) Design and endpoints of 
clinical trials in hepatocellular carcinoma. J Natl Cancer Inst 100(10): $698-711$

Llovet JM, Real MI, Montana X, Planas R, Coll S, Aponte J, Ayuso C, Sala M, Muchart J, Sola R, Rodes J, Bruix J (2002) Arterial embolisation or chemoembolisation versus symptomatic treatment in patients with unresectable hepatocellular carcinoma: a randomised controlled trial. Lancet 359(9319): 1734-1739

Llovet JM, Ricci S, Mazzaferro V, Hilgard P, Gane E, Blanc JF, de Oliveira AC, Santoro A, Raoul JL, Forner A, Schwartz M, Porta C, Zeuzem S, Bolondi L, Greten TF, Galle PR, Seitz JF, Borbath I, Haussinger D, Giannaris T, Shan M, Moscovici M, Voliotis D, Bruix J, the SHARP Investigators Study Group (2008b) Sorafenib in advanced hepatocellular carcinoma. N Engl J Med 359(4): 378-390

Maruyama H, Yoshikawa M, Yokosuka O (2008) Current role of ultrasound for the management of hepatocellular carcinoma. World J Gastroenterol 14(11): $1710-1719$

Mazzaferro V, Regalia E, Doci R, Andreola S, Pulvirenti A, Bozzetti F, Montalto F, Ammatuna M, Morabito A, Gennari L (1996) Liver transplantation for the treatment of small hepatocellular carcinomas in patients with cirrhosis. N Engl J Med 334(11): 693-700

Pasche B, Erman M, Hayduk R, Mitler M, Reite M, Higgs L, Dafni U, Amato D, Rossel C, Kuster N, Barbault A, Lebet JP (1996) Effects of low energy emission therapy in chronic psychophysiological insomnia. Sleep 19: 327-336

Pasche B, Erman M, Mitler M (1990) Diagnosis and management of insomnia. $N$ Engl J Med 323: 486-487

Pasche B, Barbault A (2003) Low-energy emission therapy: current status and future directions. In Bioelectromagnetic Medicine, Rosch PJ, Markov MS (eds) pp 321 - 327. Marcel Dekker Inc.: New York, NY
Reite M, Higgs L, Lebet JP, Barbault A, Rossel C, Kuster N, Dafni U, Amato D, Pasche B (1994) Sleep inducing effect of low energy emission therapy. Bioelectromagnetics 15: $67-75$

Riaz A, Ryu RK, Kulik LM, Mulcahy MF, Lewandowski RJ, Minocha J, Ibrahim SM, Sato KT, Baker T, Miller FH, Newman S, Omary R, Abecassis M, Benson III AB, Salem R (2009) Alpha-fetoprotein response after locoregional therapy for hepatocellular carcinoma: oncologic marker of radiologic response, progression, and survival. J Clin Oncol 27(34): $5734-5742$

Siegel AB, Cohen EI, Ocean A, Lehrer D, Goldenberg A, Knox JJ, Chen H, Clark-Garvey S, Weinberg A, Mandeli J, Christos P, Mazumdar M, Popa E, Brown RSJ, Rafii S, Schwartz JD (2008) Phase II trial evaluating the clinical and biologic effects of bevacizumab in unresectable hepatocellular carcinoma. J Clin Oncol 26(18): 2992-2998

Simon R (1989) Optimal two-stage designs for phase II clinical trials. Control Clin Trials 10(1): $1-10$

Therasse P, Arbuck SG, Eisenhauer EA, Wanders J, Kaplan RS, Rubinstein L, Verweij J, Van Glabbeke M, van Oosterom AT, Christian MC, Gwyther SG (2000) New guidelines to evaluate the response to treatment in solid tumors. J Natl Cancer Inst 92(3): 205-216

Thomas MB, Zhu AX (2005) Hepatocellular carcinoma: the need for progress. J Clin Oncol 23(13): 2892-2899

cc)(ㄱ) This work is licensed under the Creative Commons (c) BY NC SA Attribution-NonCommercial-Share Alike 3.0 Unported License. To view a copy of this license, visit http://creativecommons. org/licenses/by-nc-sa/3.0/ 